\title{
Immunophenotyping of cerebrospinal fluid cells by Chipcytometry
}

\author{
Martin W. Hümmert ${ }^{1 \dagger}$, Sascha Alvermann ${ }^{1+}$, Stefan Gingele ${ }^{1}$, Catharina C. Gross ${ }^{2}$, Heinz Wiendl ${ }^{2}$, Anja Mirenska ${ }^{3}$, \\ Christian Hennig $^{3}$ and Martin Stangel ${ }^{1^{*}}$
}

\begin{abstract}
Background: The gold standard in cerebrospinal fluid (CSF) cell immunophenotyping is flow cytometry. Nevertheless, the small amount of CSF cells and the invasive character of lumbar puncture limit the spectrum of possible investigation. Chipcytometry, a modified approach to slide-based cytometry, might be a useful tool for CSF analysis due to the possibility of iterative staining, imaging, and bleaching cycles. The aim of this study was to compare flow cytometric leukocyte subset analysis with Chipcytometry comparing the percentage distribution of distinct cell populations and the T-cell CD4:CD8 ratio. Moreover, this study investigated the interpretability of chips loaded with CSF cells and examined the applicability of Chipcytometry in clinical practice.
\end{abstract}

Methods: 375 CSF samples from 364 patients were analyzed by Chipcytometry using an automated upright microscope. Cell surface molecules were stained using fluorescence-labeled monoclonal antibodies. For crossvalidation experiments, flow cytometry data of six patients were analyzed and matched with Chipcytometry data.

Results: Our experiments showed a better agreement examined by Bland-Altman analysis for samples with CSF pleocytosis than for normocellular CSF samples. Data were more consistent for B cells and CD4:CD8 ratio than for T cells and monocytes. Advantages of Chipcytometry compared to flow cytometry are that cells once fixated can be analyzed for up to 20 months with additional markers at any time. The clinical application of Chipcytometry is demonstrated by two illustrative case reports. However, the low amount of CSF cells limits the analysis of normocellular CSF samples, as in our cohort only $11.7 \%$ of respectively loaded chips had sufficient cell density for further investigation compared to $59.8 \%$ of all chips loaded with samples with elevated cell counts $(\geq 5 / \mu l)$. Varying centrifuge settings, tube materials and resuspension technique were not able to increase the cell yield.

Conclusion: In summary, the results demonstrate the great potential of Chipcytometry of CSF cells for both scientific questions and routine diagnostic. A new chip design optimized to meet the requirements of CSF would greatly enhance the value of this method. Cross-validation results need to be confirmed in a larger cohort.

Keywords: Immunophenotype, CSF, Cerebrospinal fluid, Flow cytometry, Slide-based cytometry, Chipcytometry

\section{Background}

Immunophenotyping of cerebrospinal fluid (CSF) cells by flow cytometry has helped to elucidate the pathophysiology of inflammatory neurological disorders such as multiple sclerosis (MS) [1]. Furthermore, knowledge of the immune cell composition in the CSF can have prognostic value and

\footnotetext{
* Correspondence: stangel.martin@mh-hannover.de

${ }^{\dagger}$ Martin W. Hümmert and Sascha Alvermann contributed equally to this work.

${ }^{1}$ Department of Neurology and Department of Clinical Neuroimmunology and Neurochemistry, Hannover Medical School, Carl-Neuberg-Str. 1, 30625 Hannover, Germany

Full list of author information is available at the end of the article
}

might therefore be useful to assist treatment decisions [2]. However, although CSF is collected as part of the diagnostic work-up in many neurological conditions, immunophenotyping of CSF cells by flow cytometry is rarely used in clinical routine. This is due to a number of limitations that arise when dealing with CSF cell samples. First, CSF withdrawal by lumbar puncture is an invasive procedure that is not without side effects and is perceived as painful by most patients. Therefore it is performed only once during the diagnostic work-up in most cases. Unfortunately, flow cytometry does not allow for storing and repeated analysis of samples. As it relies on a predefined set of markers that has

(C) The Author(s). 2018 Open Access This article is distributed under the terms of the Creative Commons Attribution 4.0 International License (http://creativecommons.org/licenses/by/4.0/), which permits unrestricted use, distribution, and 
to be established before the sample is processed, flow cytometry cannot be easily adjusted if new clinical questions or hypotheses arise during the analysis. In addition, the cellular content of CSF is very low compared to peripheral blood, making it difficult to obtain sufficient cell numbers in paucicellular samples for detailed analysis. Furthermore, cell viability in CSF ex vivo is poor leading to a rapid decline in cell numbers after sample collection [3].

To exploit the full potential of CSF analysis for diagnostic and scientific purposes, a new method for immunophenotyping of CSF cells is highly desirable. Ideally, it should require only small amounts of cells and be available within a short time after sample collection in order to meet the constraints of low cellularity and poor cell viability. Furthermore, it should have the potential for storing and reanalyzing samples so that maximum information can be gained from a single sample and repeated lumbar punctures are unnecessary even if new questions are to be addressed.

Slide-based cytometry was first introduced in 1997 as an alternative to flow cytometry [4]. Briefly, this method is based on automated epifluorescence microscopy of cells that are immobilized on a solid surface. Since then, this concept has been refined in order to meet the requirements for peripheral blood cell analysis [5, 6] with iterative restaining [7] and photobleaching of fluorochromes [8] as newly introduced components. Chipcytometry is a modified approach to slide-based cytometry developed at the Hannover Medical School. It is based on microfluidic chips containing cell-adhesive surfaces that allow for quick and easy sample preparation, long-term storage, and repeated staining and washing steps by simple fluid exchange [9]. Through iterative staining-imaging-bleaching cycles, a theoretically unlimited number of cellular markers can be analyzed in a single sample.

So far, Chipcytometry has mostly been applied to study human peripheral blood mononuclear cells (PBMC) $[10,11]$ and bronchoalveolar lavage cells [12]. We aimed to investigate whether Chipcytometry is a suitable method for immunophenotyping of CSF cells.

\section{Methods}

\section{Patients and sample collection}

Patients were recruited at the Department of Neurology at Hannover Medical School, Germany, and the Department of Neurology at the University of Münster, Germany. The study was approved by the local ethics committee (no. 1322-2012) and all patients gave written consent before enrollment. In total, 375 CSF samples (Hannover: 364, Münster: 11) were collected from 364 patients (Hannover: 353, Münster: 11) between March 2012 and February 2016 (Table 1). Lumbar punctures were part of routine diagnostics or, in the case of two
Table 1 Number of CSF samples related to group of diseases, patient age and sex

\begin{tabular}{llll}
\hline Group of diseases & $\begin{array}{l}\text { Patients } \\
n\end{array}$ & $\begin{array}{l}\text { Age, years } \\
\text { Range (median) }\end{array}$ & $\begin{array}{l}\text { Sex } \\
\text { f:m (percentage) }\end{array}$ \\
\hline All & 364 & $17-85(51)$ & $178: 186(49: 51)$ \\
MS/CIS & 76 & $17-78(41)$ & $50: 26(66: 34)$ \\
OIND - infectious & 12 & $27-78(46)$ & $8: 4(67: 33)$ \\
OIND - autoimmune & 54 & $18-79(48)$ & $29: 25(54: 46)$ \\
Tumor & 18 & $28-84(64,5)$ & $5: 13(28: 72)$ \\
NIND & 167 & $20-85(60)$ & $69: 98(41: 59)$ \\
NND & 35 & $18-81(41)$ & $17: 18(49: 51)$ \\
Unspecified & 2 & 20,55 & $0: 2(0: 100)$
\end{tabular}

MS multiple sclerosis, CIS clinical isolated syndrome, OIND other inflammatory neurological disease, NIND non-inflammatory neurological disease, NND non-neurological disease

patients, were performed repeatedly for intrathecal drug injections. In addition to the routine procedures up to $5 \mathrm{ml}$ of CSF were collected for study purposes. In some cases where normal pressure hydrocephalus was suspected, large volumes of CSF were withdrawn and up to $15 \mathrm{ml}$ were used for the study.

\section{Sample preparation}

CSF was collected in $15 \mathrm{ml}$ conical bottom tubes. For study purposes, we used tubes from two different materials (polypropylene, Greiner Bio-One, Austria; or polystyrene, Sarstedt, Germany). After lumbar puncture, CSF leukocytes and erythrocytes were immediately counted in a Fuchs-Rosenthal chamber. Cells were separated from CSF by centrifugation (10 min, Centrifuge 5810R, Eppendorf, Germany). For comparison of cell yield centrifuge settings varied (G: 140,1000 , or $2400 \times$ g; temperature: 4 or $20{ }^{\circ} \mathrm{C}$ ). The cell-free supernatant was carefully withdrawn with a pipette, leaving a volume of no more than $50 \mu \mathrm{l}$ that was used for resuspension of the cell pellet. The suspension was then pipetted into a microfluidic chip containing a glass surface covered with oligonucleotides for nonselective cell binding. After an incubation time of $10 \mathrm{~min}$ at room temperature, the chip's microfluidic channel was filled with $4 \%$ phosphate-buffered formaldehyde (Carl Roth, Germany) and stored at $4{ }^{\circ} \mathrm{C}$ for $15 \mathrm{~min}$. Then, the channel was rinsed with phosphate-buffered saline (PBS). Afterwards, the chip was ready for staining with fluorescent dyes or for long-term storage at $4{ }^{\circ} \mathrm{C}$.

\section{Staining and data acquisition}

For data acquisition with Chipcytometry, samples were processed as previously described [9]. Briefly, the method is based on iterative cycles of staining, imaging, and bleaching (Fig. 1). Each cellular biomarker was assessed separately, and no multicolor staining was used in order to avoid the need for compensation steps. Cell surface molecules were 


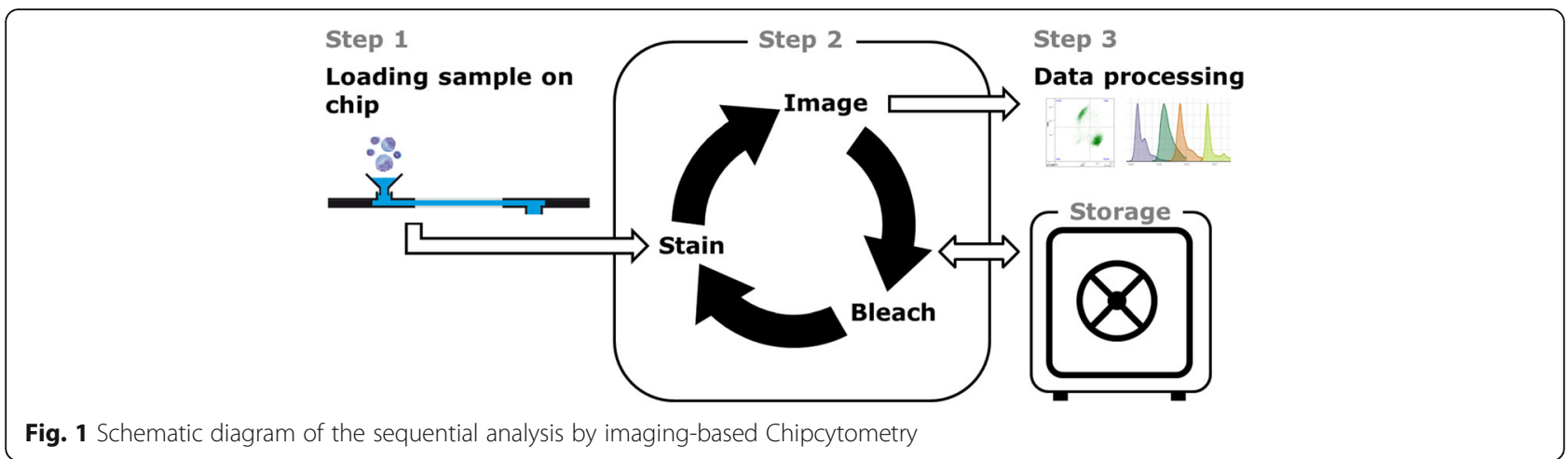

stained using phycoerythrin (PE)-labeled monoclonal antibodies diluted in PBS as indicated in Table 2 (A). For staining, the microfluidic channel was filled with the respective antibody solution and incubated for $5 \mathrm{~min}$ at room temperature. Then, the chip was rinsed with PBS and applied to the imaging system. For imaging, an automated upright microscope (modified Axio Observer Z1, Zeiss, Germany) was used as detailed previously [9]. For every position, two images (fluorescence light mode and transmitted light mode) were acquired. Afterwards, the remaining fluorescence was bleached by extended illumination to allow for staining with a new antibody.

\section{Data analysis}

Cells were distinguished from the background in transmitted light mode images by automated cell recognition [9]. However, in most cases manual corrections were necessary as some cells were missed by the algorithm and sometimes debris and foreign particles were falsely marked as cells. The mean fluorescence intensity (MFI) per cell was measured before and after each bleaching procedure. The MFI after bleaching was subtracted from the MFI of the unbleached cell to account for autofluorescence and possible local inhomogeneity of illumination. Size, coordinates on the chip, and fluorescence intensities were recorded for each cell. For further analysis, data sets were processed using an in-house software. Data were visualized either in two-dimensional (2D) plot form or as heatmap images. We used 2D plots to study cell populations in a hypothesisbased approach according to predefined gating strategies. Heatmap images were generated by cluster analysis where cells with similar biomarker expression were grouped automatically, allowing for a more exploratory approach.

\section{Cross-validation by flow cytometry}

For cross-validation experiments flow cytometry data were acquired and analyzed using a Navios ${ }^{\mathrm{Tm}}$ flow cytometer and Navios $^{\mathrm{Tw}}$ analysis software (Beckman Coulter, USA) as previously described [13]. Briefly, $3 \mathrm{ml}$ of CSF were collected in polypropylene tubes and processed within $20 \mathrm{~min}$ after lumbar puncture. Cells were
Table 2 Antibodies used for (A) Chipcytometry and (B) flow cytometry

\begin{tabular}{|c|c|c|c|}
\hline Epitope & Clone & Company & Dilution \\
\hline \multicolumn{4}{|l|}{$A$} \\
\hline CD3 & UCHT1 & $\mathrm{BD}$ & 1:100 \\
\hline CD4 & RPA-T4 & Biolegend & 1:100 \\
\hline CD8 & RPA-T8 & $\mathrm{BD}$ & $1: 30$ \\
\hline CD14 & RMO52 & Beckman Coulter & $1: 30$ \\
\hline CD16 & $3 G 8$ & Biolegend & $1: 100$ \\
\hline CD19 & HIB 19 & eBioscience & 1:100 \\
\hline CD24 & ML5 & Biolegend & $1: 300$ \\
\hline CD25 & M-A251 & $\mathrm{BD}$ & $1: 50$ \\
\hline CD27 & LG.3A10 & Biolegend & $1: 300$ \\
\hline CD38 & HB7 & $\mathrm{BD}$ & $1: 50$ \\
\hline CD45RA & HI100 & Biolegend & $1: 400$ \\
\hline CD54 & HA58 & $\mathrm{BD}$ & $1: 30$ \\
\hline CD56 & AF12-7H3 & Miltenyi Biotec & $1: 30$ \\
\hline HLA-DR & G46-6 & $\mathrm{BD}$ & $1: 50$ \\
\hline $\lg D$ & IA6-2 & Biolegend & $1: 30$ \\
\hline $\lg M$ & MHM-88 & Biolegend & $1: 250$ \\
\hline $\lg G$ & IS11-3B2.2.3 & Miltenyi Biotec & 1:100 \\
\hline $\lg A$ & IS11-8E10 & Miltenyi Biotec & $1: 200$ \\
\hline Kappa light chain & МHK-49 & Biolegend & $1: 200$ \\
\hline Lambda light chain & MHL-38 & Biolegend & 1:200 \\
\hline \multicolumn{4}{|l|}{ B } \\
\hline CD3 (PC 5.5) & UCHT1 & Beckman Coulter & $1: 200$ \\
\hline CD4 (APC) & $12 \mathrm{~B} 8.2$ & Beckman Coulter & $1: 200$ \\
\hline CD8 (pacific blue) & B9.11 & Beckman Coulter & $1: 200$ \\
\hline CD14 (FITC) & RM052 & Beckman Coulter & $1: 200$ \\
\hline CD19 (APC-A700) & J3-119 & Beckman Coulter & $1: 200$ \\
\hline CD45 (krome orange) & $J .33$ & Beckman Coulter & 1:200 \\
\hline
\end{tabular}

All antibodies used for Chipcytometry were labeled with the fluorochrome phycoerythrin (PE). The fluorochromes used in flow cytometry are indicated in parentheses 
obtained from CSF by centrifugation (15 min, $290 \times g, 4^{\circ}$ C). For erythrocyte lysis, the cell pellet was resuspended in $1 \mathrm{ml}$ VersaLyse buffer (Beckman Coulter, Germany) and was incubated for $10 \mathrm{~min}$ at room temperature. Cells were stained using fluorochrome-conjugated antibodies as indicated in Table 2 (B).

\section{Statistics}

Results were analyzed with GraphPad Prism 5.02 (GraphPad Software, USA). Statistical significance was evaluated by unpaired $t$ test or analysis of variance and the use of Bonferroni's correction. $P$ values $<0.05$ were considered as statistically significant. For cross-validation experiments, data sets from different methods (flow cytometry and Chipcytometry) were compared using Bland-Altman analysis.

\section{Results}

\section{Cell counts and density}

Out of 375 CSF samples, 283 (75.5\%) had normal cell counts $<5 / \mu \mathrm{l}$ and $92(24.5 \%)$ had a pleocytosis $(\geq 5 / \mu \mathrm{l})$. In 131 samples (34.9\%) absolute cell numbers (i.e., cell concentration multiplied by volume) were $\geq 10,000$.

After preparing a chip with a cell sample, cell density on the chip surface was first assessed visually using an upright microscope. Low cell density would make it unlikely that sufficient cell numbers would be recorded for statistical analysis. Based on preliminary experiments, we decided on a cut-off value of at least 20 cells per field of view. If cell density was lower than that, the chip was discarded for further analysis. Only $11.7 \%$ of chips loaded with normocellular samples had sufficient cell density and were analyzed further. Samples with elevated cell counts $\geq 5 / \mu \mathrm{l}$ produced better results, as $59.8 \%$ of the chips could be analyzed. Of the samples with absolute cell numbers $<10,000$ only $9 \%$ achieved a sufficient cell density, as opposed to $50.4 \%$ of samples with $\geq$ 10,000 cells (Table 3 ). For the comparison of methods, 11 samples from different patients, 2 of them with pleocytosis, were collected at the Department of Neurology at the University of Münster and were analyzed by flow cytometry on-site. For these samples, cell density for analysis by Chipcytometry was enhanced using a minimum of $3 \mathrm{ml}$ of CSF. Sufficient cell density was reached in 6 patients $(54.5 \%)$.

\section{Cell loss due to centrifugation}

The low cell densities on many chips led us to investigate cell loss during centrifugation. In a series of 11 CSF samples, absolute cell numbers were calculated before and after centrifugation $\left(1000 \times g ; 20{ }^{\circ} \mathrm{C} ; 10 \mathrm{~min}\right)$. We observed a mean cell loss of $59.3 \%$ (data not shown). We aimed to minimize cell loss by modifying centrifuge settings. However, neither varying centrifuge speed nor
Table 3 Numbers and percentages of chips with sufficient cell density subject to cell content of the CSF sample

\begin{tabular}{lll}
\hline & $n$ & Chips with sufficient cell density \\
\hline Cell count per $\mu \mathrm{l}$ & & \\
$<5$ & 283 & $33(11.7 \%)$ \\
$\geq 5$ & 92 & $55(59.8 \%)$ \\
$\geq 10$ & 57 & $37(64.9 \%)$ \\
$\geq 30$ & 25 & $20(80 \%)$ \\
$\geq 50$ & 13 & $11(84.6 \%)$ \\
Absolute cell count & & \\
$<10,000$ & 244 & $22(9 \%)$ \\
$\geq 10,000$ & 131 & $66(50.4 \%)$ \\
$\geq 50,000$ & 39 & $27(69.2 \%)$ \\
$\geq 100,000$ & 22 & $16(72.7 \%)$ \\
All samples & 375 & $88(23.5 \%)$ \\
\hline
\end{tabular}

temperature led to a significant improvement. We next evaluated whether different materials of collection tubes or different resuspension techniques had an influence on cell recovery. We found no difference between polypropylene and polystyrene tubes but resuspending cells in a larger volume (50 vs. $15 \mu \mathrm{l}$ ) after centrifugation led to a slightly increased cell yield. However, the results did not reach statistical significance (Fig. 2).

\section{Stability of cells and biomarkers}

Long-term stability of samples is an essential prerequisite for the concept of iterative cytometry. We analyzed individual samples at different time points in order to assess whether changes in biomarker expression occur with prolonged storage. For long-term storage, the chip's microfluidic channel was rinsed with PBS, sealed with plastic caps, and stored horizontally at $4{ }^{\circ} \mathrm{C}$. Figure 3 shows an exemplary sample that was analyzed immediately after preparation and then reanalyzed 20 months later. The images demonstrate a high degree of biomarker stability but also reveal one main disadvantage of the method. As cells bind to the chip surface in a noncovalent manner, cell loss due to shearing forces may occur during staining and washing. We frequently observed a decreased cell density after repeated staining and washing steps. This raised concerns that artificial phenotypes might be generated if cells marked by automated cell recognition get lost during the procedure and therefore show zero expression in the following staining/ imaging steps. We thus ran the cell recognition algorithm after completing all stainings of our panel. However, this procedure did not completely rule out the possibility of artificial phenotypes as cells would sometimes get detached during fluid exchange and then adhere to another position of the chip surface. Careful 

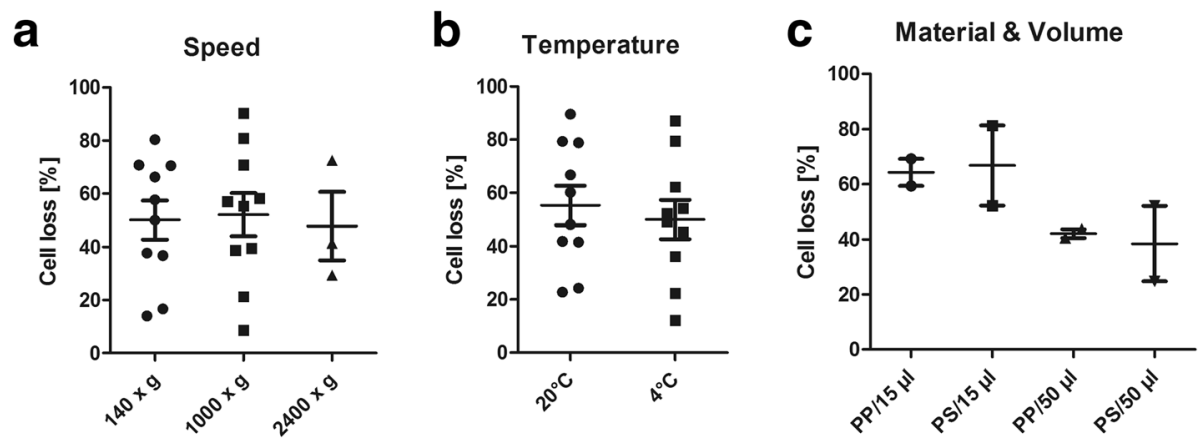

Fig. 2 Influence of centrifuge speed (a), centrifuge temperature (b), collection tube material (c), and resuspension volume (c) on cell loss during centrifugation. PP = polypropylene, $\mathrm{PS}=$ polystyrene

quality control was therefore carried out, and cells displaying artificial phenotypes were excluded manually.

\section{Cross-validation by flow cytometry}

For cross-validation the Chipcytometry data were compared with results obtained by flow cytometry. The percentage distribution of distinct cell populations $\left(\mathrm{CD}^{+} \mathrm{T}\right.$ cells, CD19 ${ }^{+} \mathrm{B}$ cells, CD14 ${ }^{+}$monocytes) and the $\mathrm{T}$ cell CD4:CD8 ratio were analyzed by both methods in the CSF of six patients. Agreement between the two methods was assessed by Bland-Altman analysis. We found a bias close to zero and a narrow 95\% limit of agreement in samples with elevated cell counts but not in normocellular samples. Smaller biases and narrower limits of agreement were observed for B cells and CD4: CD8 ratio than for $\mathrm{T}$ cells and monocytes. The most pronounced bias $(-5.420)$ was found for monocytes which may indicate a tendency of Chipcytometry to measure higher monocyte percentages than flow cytometry (Table 4 and Fig. 4). Of note, in the analyzed cohort, there is one outlier for B cells, thus this result should be interpreted with caution.

\section{Scientific application}

We applied Chipcytometry to study immune cell subsets in the CSF of MS patients. Utilizing the potential of iterative cytometry a large amount of cellular biomarkers could be analyzed in each sample. In line with previous observations from flow cytometry studies $[14,15]$, the predominant cell population consisted of $\mathrm{CD} 4^{+} \mathrm{T}$ helper cells most of which had a central memory phenotype $\left(\mathrm{CD} 27^{+}\right.$ $\mathrm{CD} 45 \mathrm{RA}^{-}$). Activation status of different $\mathrm{T}$ cell subsets was assessed by CD25, CD38, and HLA-DR staining. $\mathrm{CD} 19^{+} \mathrm{B}$ cells were frequent in the CSF which is a

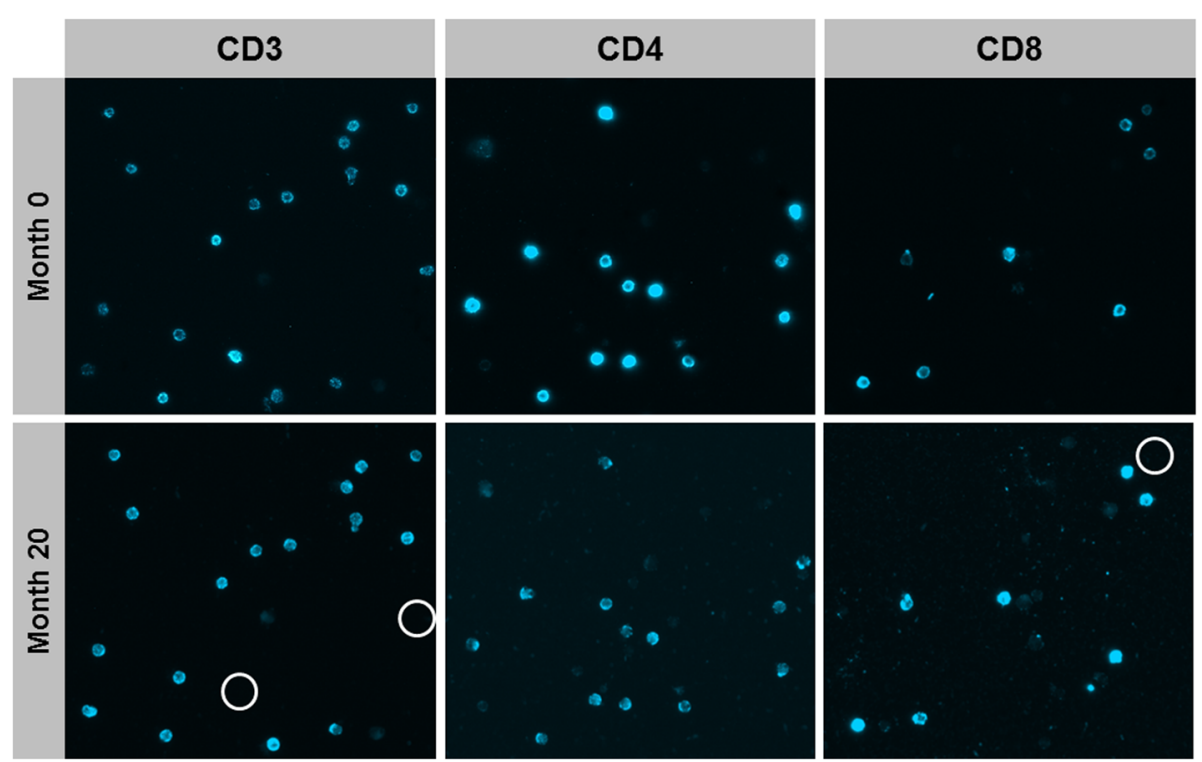

Fig. 3 Raw fluorescence light images of CSF cells obtained from a patient with clinically isolated syndrome. Stainings and measurements were performed two times 20 months apart. White circles indicate cell loss 
Table 4 Bland-Altman analysis comparing data obtained by flow cytometry and Chipcytometry

\begin{tabular}{lllc}
\hline Sample/cell population & Bias & \multicolumn{2}{l}{ 95\% limits of agreement } \\
\hline All cells and samples & -1.054 & -17.31 & 15.20 \\
Cell counts $\geq 5 / \mu \mathrm{l}$ & 0.008750 & -7.961 & 7.978 \\
Cell counts $<5 / \mu \mathrm{l}$ & -1.585 & -20.87 & 17.70 \\
T cells & 1.315 & -23.62 & 26.25 \\
B cells & -0.3833 & -4.463 & 3.696 \\
Monocytes & -5.420 & -26.62 & 15.78 \\
T cell CD4:CD8 ratio & 0.2733 & -1.638 & 2.185
\end{tabular}

A bias close to zero indicates that both methods generate nearly identical results

distinguishing feature of inflammatory central nervous system (CNS) disorders [16]. In line with published data [17], most B cells displayed a phenotype of class-switched memory cells $\left(\mathrm{CD} 27^{+} \mathrm{IgG}^{+}\right)$or plasmablasts $\left(\mathrm{CD} 19^{\text {low }}\right.$ $\mathrm{CD} 27^{+} \mathrm{CD} 38^{\text {high }}$ ). Natural killer (NK) cells and monocytes appeared in the CSF in rather low frequencies. In addition, we constantly observed a population of lineage marker negative cells with strong HLA-DR expression indicating dendritic cells (DC) [18]. In summary, all relevant CSF cell populations could be easily detected, characterized, and quantified using Chipcytometry. Figure 5 shows exemplary data of one patient with MS and one control.

\section{Application in clinical practice}

We report two cases in which Chipcytometry analysis of CSF cells proved useful in clinical routine.

\section{Case 1}

A 31-year-old woman with an unremarkable previous medical history was diagnosed with right-sided optic neuritis. MRI of brain and spinal cord showed multiple lesions with dissemination in space and in time so that a diagnosis of multiple sclerosis was made according to

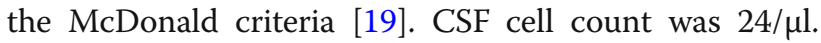
Chipcytometry revealed $79 \% \mathrm{CD}^{+} \mathrm{T}$ cells, $12 \% \mathrm{CD} 19^{+} \mathrm{B}$ cells, and $1.5 \% \mathrm{CD}^{+} 4^{+}$monocytes. T cell CD4:CD8 ratio was $2.7, \mathrm{~B}$ cell to monocyte ratio was 8.0. Fifteen percent of $\mathrm{CD} 19^{+} \mathrm{B}$ cells had a plasmablast phenotype (CD19 ${ }^{\text {low }}$ $\mathrm{CD}^{+} 7^{+} \mathrm{CD} 38^{\text {high }}$ ) (Fig. 6). A high $\mathrm{B}$ cell to monocyte ratio as in this case has been suggested to indicate rapid disease progression [2]. Immunomodulatory treatment was started immediately.

\section{Case 2}

A 78-year-old woman suspected of having normal pressure hydrocephalus unexpectedly had an elevated CSF cell count of $80 / \mu$ l. Our standard Chipcytometry panel (CD3, CD4, CD8, CD14, CD19, CD24, CD27, CD38, CD45RA, CD56, and HLA-DR) revealed a disproportionately high percentage of $\mathrm{CD} 19^{+} \mathrm{B}$ cells (84\%) raising the suspicion of
$B$ cell lymphoma. We performed additional stainings with a set of $B$ cell surface markers (IgA, IgD, IgM, IgG, $\kappa^{-}$, and $\lambda$-light chains) which proved that $B$ cells were $\operatorname{IgM}^{+}$and had $\lambda$-light chain restriction (Fig. 7). A diagnosis of lymphomatous meningitis was made and intrathecal injections of methotrexate were started.

\section{Discussion}

Immunophenotyping of CSF cells is a promising tool for diagnostic and scientific purposes. However, the invasive procedure required to collect CSF, its low cellular content, and the rapid decline of cell numbers ex vivo hamper conventional immunophenotyping by flow cytometry. The ideal method to analyze CSF cells would therefore require only small amounts of cells, be available immediately after sample collection, be able to measure multiple biomarkers in a single sample, and allow for long-term storage and reassessment of samples even at a different site. Chipcytometry was originally designed to address similar issues, albeit in the setting of pediatric patients with hematologic diseases [11]. As frequent blood withdrawal is stressful for severely ill children, a way to obtain as much information as possible from very small blood samples was sought. Chipcytometry has since proved useful in a number of clinical settings and with different sample materials [10-12].

In this work, we tested whether Chipcytometry is a suitable method for immunologic characterization of CSF cells. Our first observation was that the majority of CSF samples with normal cell counts $<5 / \mu$ l could not be analyzed due to insufficient cell density on the chip surface. There are two main problems with low cell density. First, more positions (microscope fields of view) of the surface must be scanned to collect a sufficient number of cells. While the scanning procedure is rather quick, the bleaching step requires $30 \mathrm{~s}$ per position in the current setting. Therefore, lower cell densities account for increasingly time-consuming data acquisition. For 50 positions, bleaching alone would take $25 \mathrm{~min}$ in each staining-imaging-bleaching cycle. The second problem is that cell recognition depends on proper imaging, i.e., correct focus and exact repositioning in each cycle. These steps are fully automated but get increasingly error-prone when fewer cells per position are available. We aimed to increase cell yield by varying centrifuge settings, tube materials, and resuspension technique but did not achieve a relevant improvement. As a consequence, to achieve higher cell density either sample volumes must be increased or the surface area on which the cells are immobilized must be scaled down. In summary, in the current setting the amount of cells required is not sufficient for reliable analysis by Chipcytometry in the majority of normocellular CSF samples.

Another problem we encountered more frequently than expected was cell loss after staining or washing. Shearing 

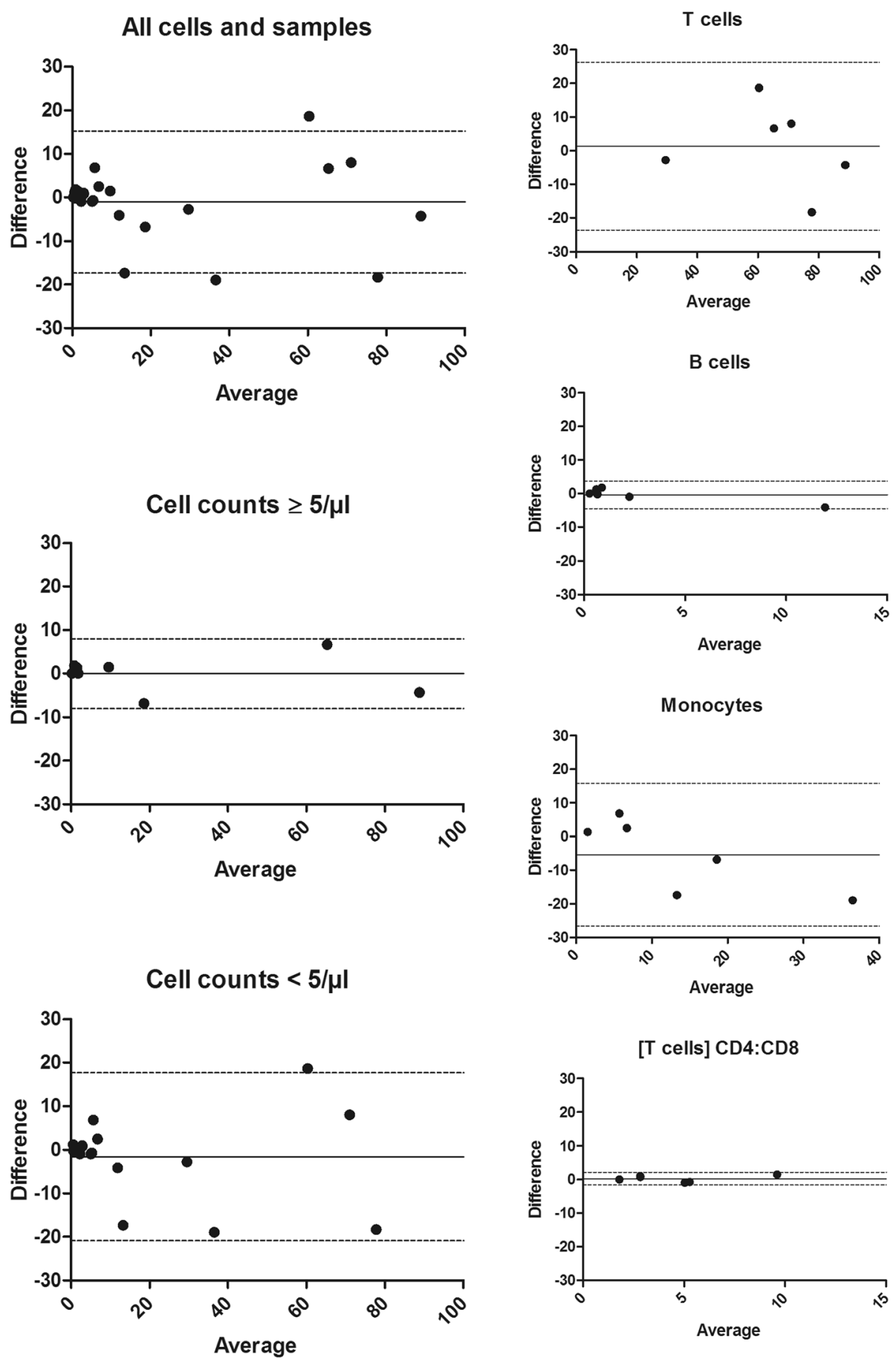

[T cells] CD4:CD8

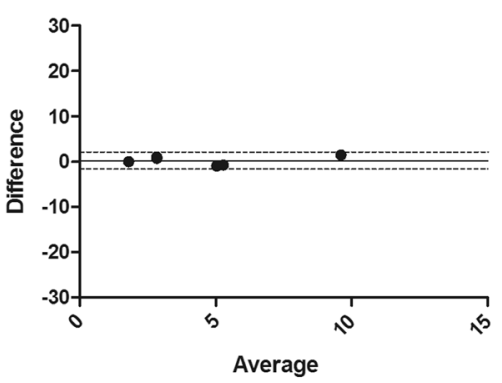

Fig. 4 Bland-Altman plots comparing data obtained by Chipcytometry and flow cytometry. X-axes show average values of both measurements, $y$-axes show the difference between both values. Bias (continuous line) and $95 \%$ limits of agreement (dotted line) are indicated. All samples: $n=6$, samples with cell counts $\geq 5 / \mu l: n=2$

forces on the chip surface are unavoidable during fluid exchange; however, we assume that suboptimal adhesive properties of CSF cells contribute to the problem as relevant cell loss was not reported in other Chipcytometry studies with different sample sources [9]. While specific cell adhesion molecules like LFA-1 and VLA-4 are generally overexpressed on CSF cells compared to peripheral blood [20] this is not likely to affect the non-selective binding to oligonucleotides involved in this method. On the contrary, the adverse characteristics of CSF that lead 
a

[All cells]

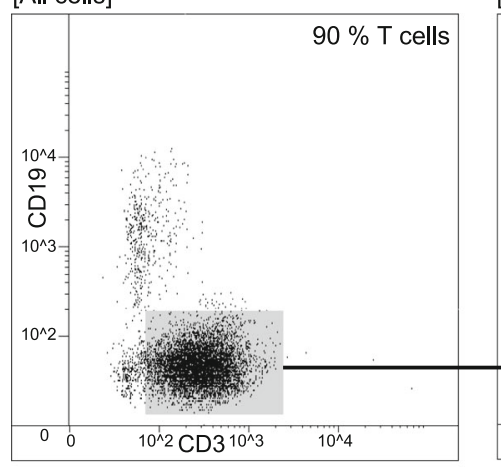

[All cells]

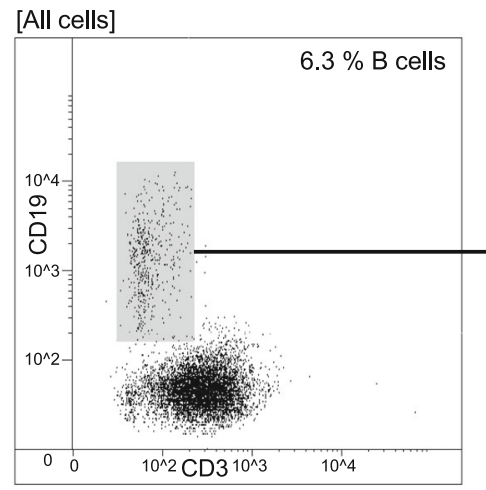

b
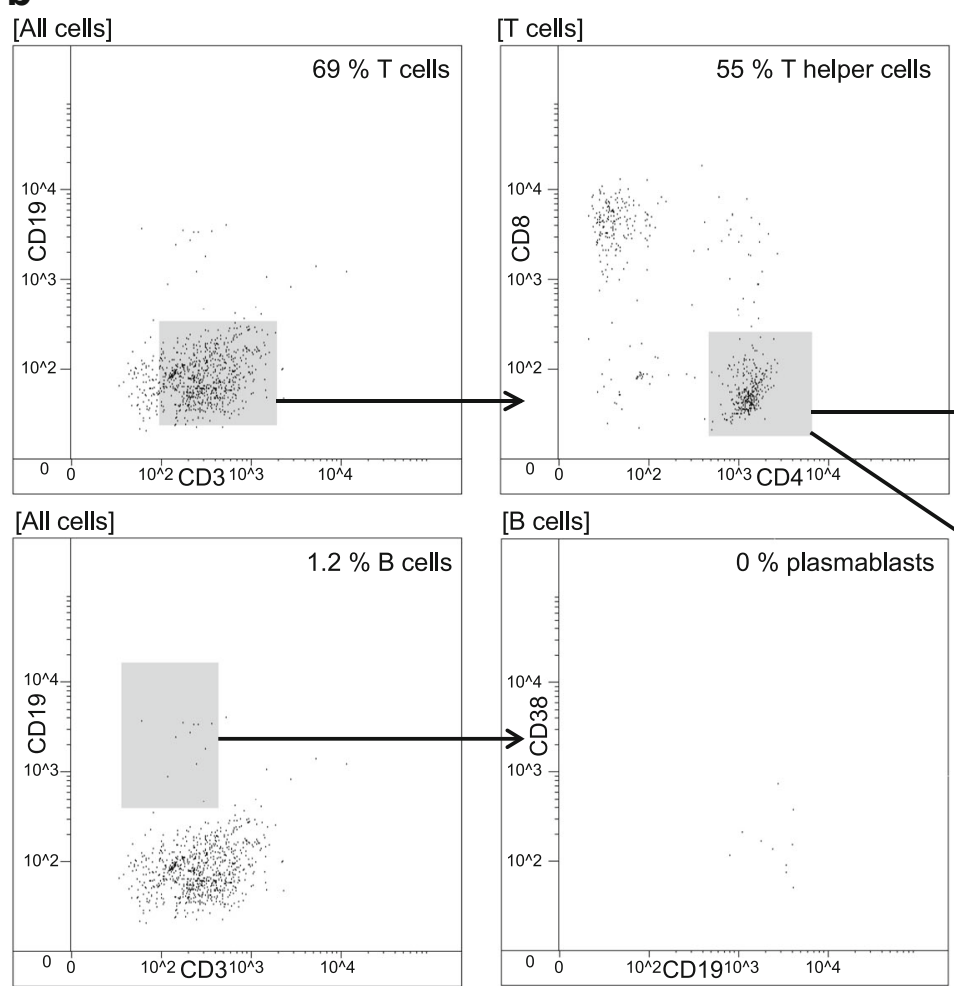

[T helper cells]
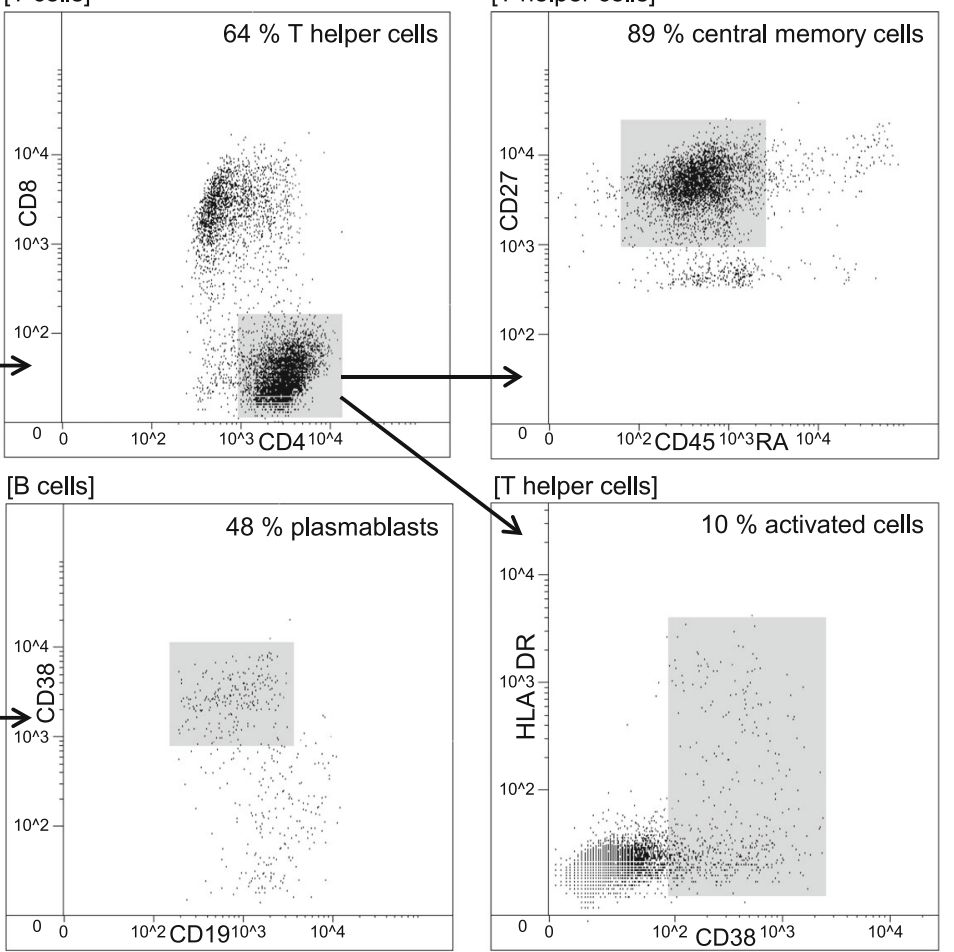

[T helper cells]

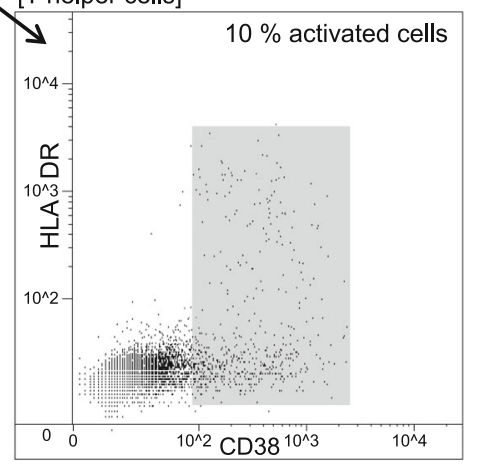

[T cells]

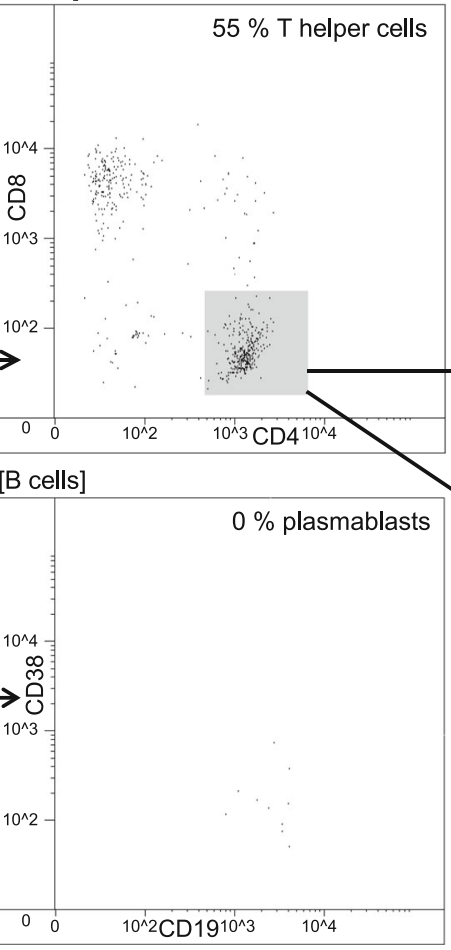

[T helper cells]

$89 \%$ central memory cells

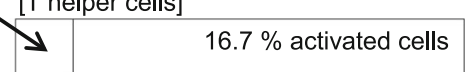

Fig. 5 Chipcytometry analysis of CSF obtained from a patient with MS (a) and a patient with tension headache (b). Expansion of B cells and plasmablasts is evident in the CSF of the MS patient compared to the headache patient 


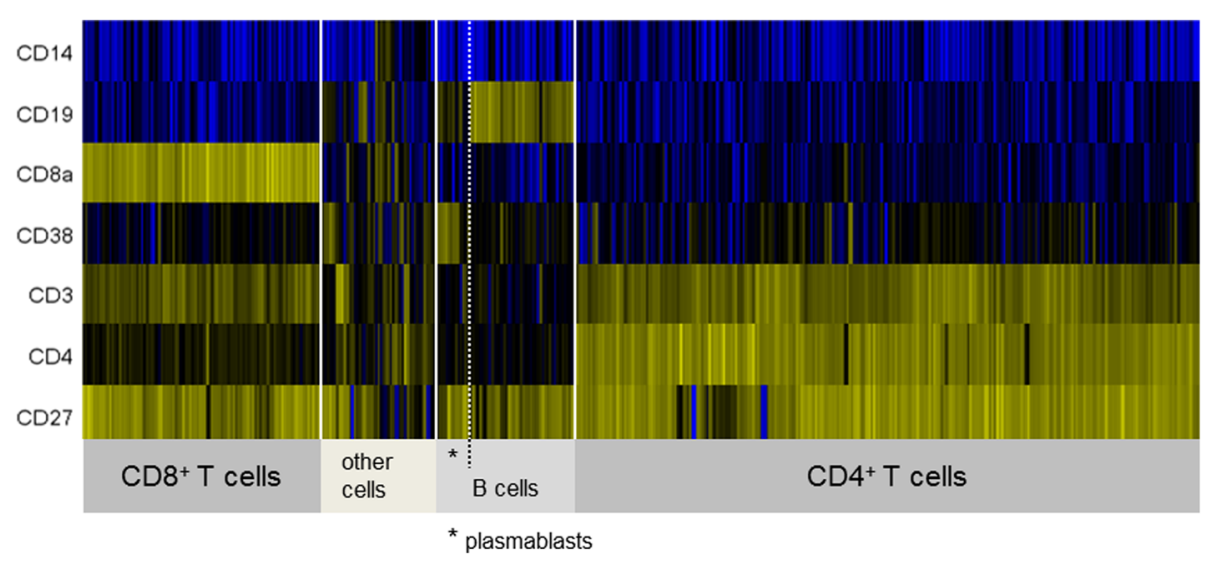

Fig. 6 Chipcytometry analysis of CSF cells obtained from a patient with optic neuritis. Heatmap generated by cluster analysis. Note large population of B cells and plasmablasts

to rapid cell death ex vivo might also alter membrane properties so that adhesive forces are reduced.

Despite these drawbacks some definite advantages of Chipcytometry over conventional approaches can be determined. Preanalytic sample handling is quick and simple so that cells can be fixated on the chip within $40 \mathrm{~min}$ from lumbar puncture. Once fixated, the cells can be analyzed at a later time point or at multiple time points, also at a different site. We found excellent biomarker stability even up to 20 months after sample preparation (Fig. 3). There are different cell-stabilizing solutions available for flow cytometry, but none of these provide long-term biomarker stability. Furthermore, the possibility to measure a theoretically unlimited number of biomarkers in a single sample is a major advantage of this method. Importantly, it is not necessary to decide on a fixed set of markers beforehand. Establishing additional markers is possible at any time because no compensation steps are required as in multicolor flow cytometry. The case of our patient with unexpected lymphomatous meningitis illustrates
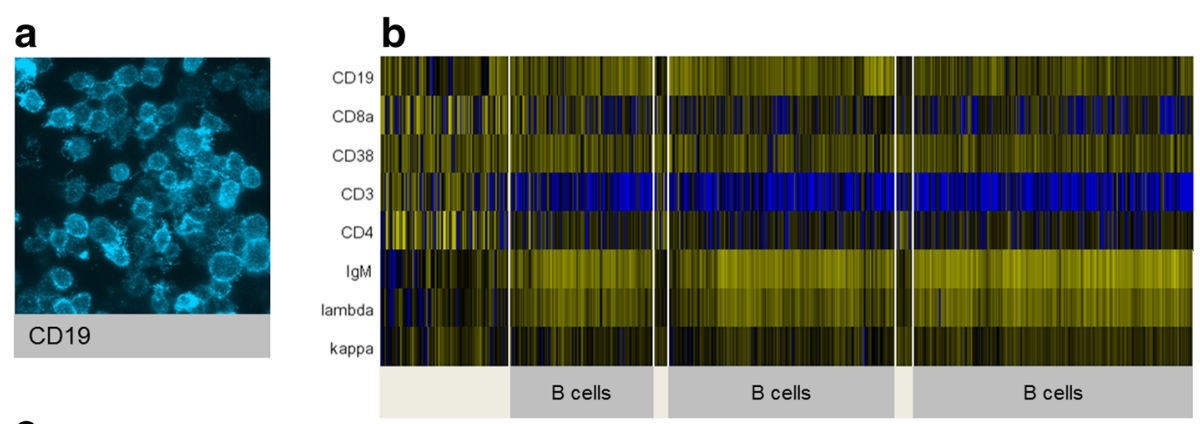

\section{C}

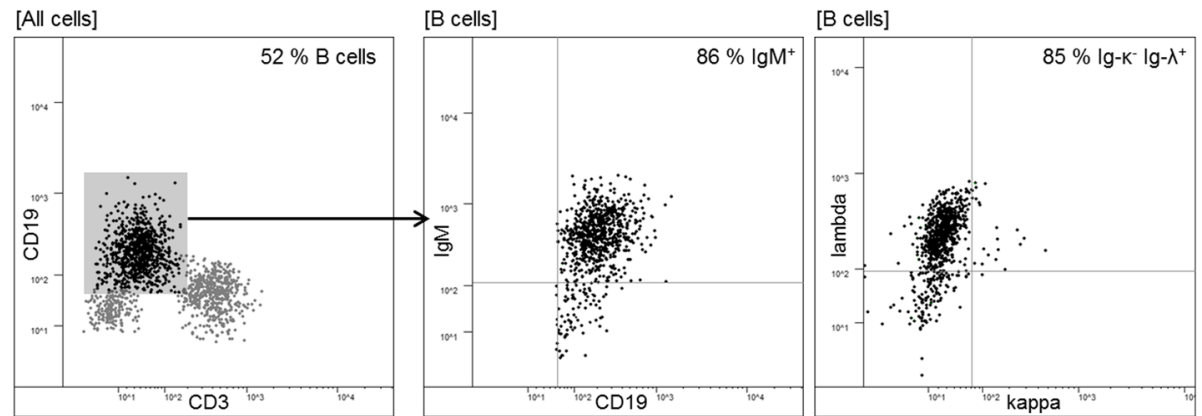

Fig. 7 Chipcytometry analysis of CSF cells in a patient with lymphomatous meningitis. a Raw image (fluorescence light mode) of CD19expressing B cells. $\mathbf{b}$ Heatmap showing a large fraction of B cells with uniform expression of IgM and $\lambda$-light chains. $\mathbf{c} 2 \mathrm{D}$ plot of CSF cells at a later date (lumbar puncture was repeated for intrathecal drug injections) 
how this increased flexibility can be highly useful in clinical diagnostics.

As there are several methodical differences between Chipcytometry and flow cytometry, cross-validation of the new method by the established standard is important. Our experiments showed a high grade of concordance between both methods in general. However, there were differences in regard to the cellularity of the samples and the analyzed cell populations. In samples with elevated cell counts, we found a better agreement between Chipcytometry and flow cytometry than in normocellular samples. It is to be expected that the error margin increases when fewer cells are detected. However, the results may also be explained by the fact that automated cell recognition is less accurate when cell density is low.

Both methods showed a very high grade of concordance when $\mathrm{T}$ cell CD4:CD8 ratios were analyzed. However, the results were slightly less congruent for $\mathrm{T}$ cell and monocyte fractions. Monocytes in particular appear to be slightly overestimated by Chipcytometry compared to flow cytometry. This may likely be explained by different gating strategies. In flow cytometry lymphocytes and monocytes are usually identified according to their light scattering properties. In our cross-validation experiments, we used forward scatter and CD45 for gating of leukocytes and then side scatter and CD14 to distinguish between lymphocytes, monocytes, and granulocytes. In Chipcytometry light scattering properties are not routinely measured, we thus relied only on lineage marker expression to identify cell populations. However, we cannot completely rule out the possibility that monocytes are positively selected during sample preparation because they might adhere stronger to the chip surface than lymphocytes.

\section{Conclusions}

In summary, our results demonstrate the great potential of Chipcytometry of CSF cells for both scientific questions and routine diagnostic. However, the main problem with CSF cell analysis by Chipcytometry is the low amount of cells. The microfluidic chips used in this study were designed for peripheral blood which has a more than 1000-fold higher leukocyte concentration than CSF. We think that a new chip design optimized to meet the requirements of CSF, e.g., a reduced surface area with increased adhesive properties, would greatly enhance the value of this method. At the present time, however, Chipcytometry cannot be recommended for routine analysis of normocellular CSF samples hence flow cytometry remains the method of choice. Moreover, the results of cross-validation between flow cytometry and Chipcytometry need to be confirmed in a larger cohort, as the amount of six patients is a clear limitation of this study.

\begin{abstract}
Abbreviations
CIS: Clinical isolated syndrome; CNS: Central nervous system;

CSF: Cerebrospinal fluid; DC: Dendritic cells; MFI: Mean fluorescence intensity; MRI: Magnetic resonance imaging; MS: Multiple sclerosis; NIND: Noninflammatory neurological disease; NK cells: Natural killer cells; NND: Nonneurological disease; OIND: Other inflammatory neurological disease; PBMC: Peripheral blood mononuclear cells; PBS: Phosphate-buffered saline; PE: Phycoerythrin; PP: Polypropylene; PS: Polystyrene
\end{abstract}

\section{Acknowledgements}

The authors thank Karin Fricke and Sabine Lang for their excellent technical support.

\section{Funding}

This research was supported by the German Ministry for Education and Research (BMBF) as part of the German Competence Network Multiple Sclerosis (KKNMS, Krankheitsbezogenes Kompetenznetz Multiple Sklerose) grant number 01GI1208B and 01Fl1603A, the Erwin-Röver-Foundation and the SFB/CRC Transregio 128 A09 and Z02. The funders had no role in study design, data collection and analysis, decision to publish, or preparation of the manuscript.

\section{Availability of data and materials}

The datasets generated and analyzed during the current study are not publicly available due to local data protection requirements but are available from the corresponding author on reasonable request in an anonymized fashion.

\section{Authors' contributions}

$\mathrm{MWH}, \mathrm{SA}, \mathrm{CH}$, and MS conceived and designed the experiments. MWH and SA performed the experiments. MWH, SA, AM, and MS analyzed and interpreted the data. CCG supervised flow cytometry and analyzed data. MWH, SA, SG, CCG, HW, AM, CH, and MS contributed reagents/materials/ analysis tools. MWH, SA, and MS wrote the paper. All authors were involved in revising the manuscript for intellectual content. All authors read and approved the final manuscript.

\section{Ethics approval and consent to participate}

The study was approved by the local ethics committee (no. 1322-2012), and all patients gave written informed consent.

\section{Consent for publication}

Participants gave written informed consent for publication.

\section{Competing interests}

$\mathrm{MWH}$ has received travel grants for attending meetings from Novartis and Bayer HealthCare, none related to this study. CCG received speaker honoraria and travel expenses for attending meetings from Biogen, Genzyme, Novartis Pharma GmbH, and Bayer HealthCare, none of these related to the current study. HW receives honoraria for acting as a member of Scientific Advisory Boards and as consultant for Biogen, Evgen, MedDay Pharmaceuticals, Merck Serono, Novartis, Roche Pharma AG, Sanofi-Genzyme, as well as speaker honoraria and travel support from Alexion, Biogen, Cognomed, F. Hoffmann-La Roche Ltd., Gemeinnützige Hertie-Stiftung, Merck Serono, Novartis, Roche Pharma AG, Sanofi-Genzyme, TEVA, and WebMD Global. He is acting as a paid consultant for Abbvie, Actelion, Biogen, IGES, Novartis, Roche, Sanofi-Genzyme, and the Swiss Multiple Sclerosis Society. His research is funded by the Deutsche Forschungsgesellschaft (DFG), Else Kröner Fresenius Foundation, Fresenius Foundation, Hertie Foundation, NRW Ministry of Education and Research, Interdisciplinary Center for Clinical Studies (IZKF) Muenster and RE Children's Foundation, Biogen $\mathrm{GmbH}$, GlaxoSmithKline GmbH, Roche Pharma AG, Sanofi-Genzyme. None of these is related to the present publication. His research is also funded by the German Ministry for Education and Research (BMBF). MS has received honoraria for scientific lectures or consultancy from Alexion, Bayer HealthCare, Biogen, Baxalta/Shire, CSL Behring, Grifols, MedDay, Merck-Serono, Novartis, Roche, Sanofi-Genzyme, and Teva. His institution received research support from Bayer HealthCare, Biogen, Genzyme,

Merck-Serono, Novartis, and Teva. None of this was related to this project. CH is incorporator and head of Zellkraftwerk $\mathrm{GmbH}$. The other authors declare that they have no competing interests. 


\section{Publisher's Note}

Springer Nature remains neutral with regard to jurisdictional claims in published maps and institutional affiliations.

\section{Author details}

'Department of Neurology and Department of Clinical Neuroimmunology and Neurochemistry, Hannover Medical School, Carl-Neuberg-Str. 1, 30625 Hannover, Germany. ${ }^{2}$ Department of Neurology, University Hospital Münster, Münster, Germany. ${ }^{3}$ Zellkraftwerk GmbH, Hannover, Germany.

Received: 17 January 2018 Accepted: 24 April 2018

Published online: 25 May 2018

\section{References}

1. Alvermann S, Hennig C, Stuve O, Wiendl H, Stangel M. Immunophenotyping of cerebrospinal fluid cells in multiple sclerosis: in search of biomarkers. JAMA Neurol. 2014;71:905-12.

2. Cepok S, Jacobsen M, Schock S, Omer B, Jaekel S, Boddeker I, Oertel WH, Sommer N, Hemmer B. Patterns of cerebrospinal fluid pathology correlate with disease progression in multiple sclerosis. Brain. 2001;124:2169-76. Epub 2001/10/24

3. de Graaf MT, de Jongste AH, Kraan J, Boonstra JG, Sillevis Smitt PA, Gratama JW. Flow cytometric characterization of cerebrospinal fluid cells. Cytometry B Clin Cytom. 2011;80:271-81.

4. Clatch RJ, Walloch JL. Multiparameter immunophenotypic analysis of fine needle aspiration biopsies and other hematologic specimens by laser scanning cytometry. Acta Cytol. 1997:41:109-22. Epub 1997/01/01

5. Gerstner A, Laffers W, Bootz F, Tarnok A. Immunophenotyping of peripheral blood leukocytes by laser scanning cytometry. J Immunol Methods. 2000; 246:175-85.

6. Gerstner AO, Mittag A, Laffers W, Dahnert I, Lenz D, Bootz F, Bocsi J, Tarnok A. Comparison of immunophenotyping by slide-based cytometry and by flow cytometry. J Immunol Methods. 2006;311:130-8.

7. Laffers W, Mittag A, Lenz D, Tarnok A, Gerstner AO. Iterative restaining as a pivotal tool for n-color immunophenotyping by slide-based cytometry. Cytometry A. 2006;69:127-30. Epub 2006/02/16

8. Mittag A, Lenz D, Bocsi J, Sack U, Gerstner AO, Tarnok A. Sequential photobleaching of fluorochromes for polychromatic slide-based cytometry. Cytometry A. 2006;69:139-41.

9. Hennig C, Adams N, Hansen G. A versatile platform for comprehensive chipbased explorative cytometry. Cytometry A. 2009;75:362-70.

10. Dijkstra D, Hennig C, Witte T, Hansen G. Basophils from humans with systemic lupus erythematosus do not express MHC-II. Nat Med. 2012;18:4889; author reply 9-90. Epub 2012/04/07

11. Hennig C, Baumann U, Ilginus C, Horneff G, Foell J, Hansen G. Successful treatment of autoimmune and lymphoproliferative complications of patients with intrinsic B-cell immunodeficiencies with rituximab. $\mathrm{Br}$ J Haematol. 2010;148:445-8. Epub 2009/11/20

12. Dijkstra D, Hennig C, Hansen G, Biller H, Krug N, Hohlfeld JM. Identification and quantification of basophils in the airways of asthmatics following segmental allergen challenge. Cytometry A. 2014;85:580-7. Epub 2014/04/16

13. Lueg G, Gross CC, Lohmann H, Johnen A, Kemmling A, Deppe M, Groger J, Minnerup J, Wiendl H, Meuth SG, Duning T. Clinical relevance of specific Tcell activation in the blood and cerebrospinal fluid of patients with mild Alzheimer's disease. Neurobiol Aging. 2015:36:81-9. Epub 2014/10/04

14. Oreja-Guevara C, Sindern E, Raulf-Heimsoth M, Malin JP. Analysis of lymphocyte subpopulations in cerebrospinal fluid and peripheral blood in patients with multiple sclerosis and inflammatory diseases of the nervous system. Acta Neurol Scand. 1998:98:310-3.

15. Giunti D, Borsellino G, Benelli R, Marchese M, Capello E, Valle MT, Pedemonte E, Noonan D, Albini A, Bernardi G, Mancardi GL, Battistini L, Uccelli A. Phenotypic and functional analysis of T cells homing into the CSF of subjects with inflammatory diseases of the CNS. J Leukoc Biol. 2003;73: 584-90. Epub 2003/04/26

16. Cepok S, Rosche B, Grummel V, Vogel F, Zhou D, Sayn J, Sommer N, Hartung HP, Hemmer B. Short-lived plasma blasts are the main B cell effector subset during the course of multiple sclerosis. Brain. 2005;128:1667-76. Epub 2005/04/01

17. Cepok S, von Geldern G, Grummel V, Hochgesand S, Celik H, Hartung H, Hemmer B. Accumulation of class switched lgD-lgM- memory B cells in the cerebrospinal fluid during neuroinflammation. J Neuroimmunol. 2006;180: 33-9. Epub 2006/09/06
18. Pashenkov M, Huang YM, Kostulas V, Haglund M, Soderstrom M, Link H. Two subsets of dendritic cells are present in human cerebrospinal fluid. Brain. 2001;124:480-92. Epub 2001/02/27

19. Polman CH, Reingold SC, Banwell B, Clanet M, Cohen JA, Filippi M, Fujihara K, Havrdova E, Hutchinson M, Kappos L, Lublin FD, Montalban X, O'Connor $P$, Sandberg-Wollheim $M$, Thompson AJ, Waubant $E$, Weinshenker B, Wolinsky JS. Diagnostic criteria for multiple sclerosis: 2010 revisions to the McDonald criteria. Ann Neurol. 2011;69:292-302.

20. JHSvenningsson A, Hansson GK, Andersen O, Andersson R, Patarroyo M, Stemme S. Adhesion molecule expression on cerebrospinal fluid T lymphocytes: evidence for common recruitment mechanisms in multiple sclerosis, aseptic meningitis, and normal controls. Ann Neurol. 1993:34:155-61. Epub 1993/08/01

\section{Ready to submit your research? Choose BMC and benefit from:}

- fast, convenient online submission

- thorough peer review by experienced researchers in your field

- rapid publication on acceptance

- support for research data, including large and complex data types

- gold Open Access which fosters wider collaboration and increased citations

- maximum visibility for your research: over $100 \mathrm{M}$ website views per year

At BMC, research is always in progress.

Learn more biomedcentral.com/submissions 